\title{
Symbolising spatially coincident temporal data
}

\author{
Kenneth Field \\ EsriInc,kfield@esri.com
}

Keywords: cartography, map design, data visualisation

\section{Abstract:}

During lockdown between March 2020 and March 2021 the state law in California meant we were largely restricted to staying in our own home, and certainly during the early months of the COVID-19 pandemic we were not able to go outside for much more than essential shopping and exercise. Our dog, Wisley, became a hugely important part of the daily exercise routine with his morning and evening walks. But there was also an opportunity to develop a map.

I captured GPS tracklogs while walking Wisley morning and evening; building a database of 730 walking routes. I wanted to experiment with the challenge of creating maps of a lot of coincident data, in this case overprinted lines. Increasingly, digital maps have a large amount of data that needs to be disentangled to make sense of it. Data is collected for so many coincident places and seeing them simply as data dumps does not in and of itself bring clarity or legibility to what it represents.

This talk will explore alternatives for representing coincident data, and expose what I think are best practices for this cartographic dilemma. The map also ended up becoming an animation (Figure 1) since that allowed me to incorporate the temporal dimension of the walks.

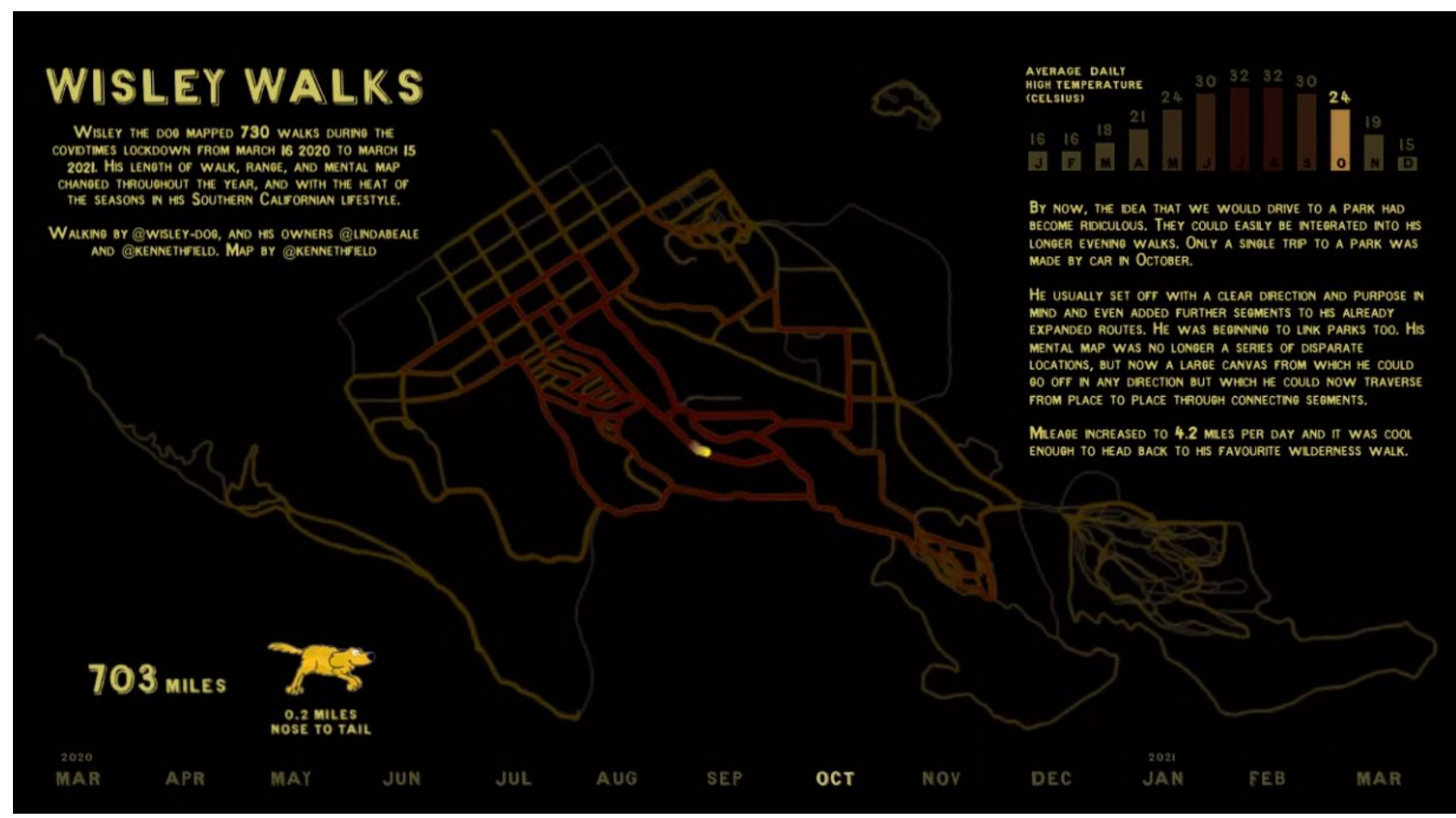

Figure 1: A still from the 20 minute animation 'Wisley Walks'

There were some interesting patterns in the data and show how our dog was challenged by the heat of the Southern Californian summer, and how his walking routes changed during the year as he clearly built a broad mental map of his environment, and joined many hitherto separate territories. 